INVESTIGACIÓN/RESEARCH

\title{
WEB 2.0 COMO ESTRATEGIA COMUNICATIVA EN LOS EVENTOS PROTOCOLARES Y DE RELACIONES PÚBLICAS. BODA REAL BRITÁNICA (24 DE ABRIL 2011)
}

\author{
Emilia Smolak-Lozano1: Universidad de Málaga. España \\ emilialozano@alu.uma.es
}

Damián García Ponce: Universidad de Málaga. España damiangponce@hotmail.com

\section{RESUMEN}

Con la explosión del recurso interactivo llamado Web 2.0, la comunicación se ha modificado, evolucionando, casi a la fuerza, para adaptarse al tiempo presente y a la fugacidad de la información dentro del nuevo horizonte comunicativo que es Internet. Las nuevas audiencias, con parámetros de exigencia distintos a la tradicionalmente pasiva audiencia audiovisual, ha requerido la realización de este esfuerzo adaptativo en materia de comunicación. Este cambio de modelo de comunicación afecta desde la retransmisión informativa hasta la de los grandes eventos internacionales protocolares y políticos, que han sufrido igualmente esta adaptación a los avances de la tecnología del Web 2.0. Adaptación que se refiere a la interactividad, participación, cercanía, a la práctica inmersión del receptor en la emisión en tiempo real. Tres grandes acontecimientos han afectado a los paradigmas de retransmisión de grandes eventos protocolares y políticos: por una parte, la boda de la Reina Isabel de Inglaterra en 1947 que fue la primera retransmisión efectuada. La segunda supuso la de mayor audiencia mundial en tiempo real: la boda de Diana de Gales y el Príncipe Carlos de Gales. El tercer evento al que hacemos referencia, y al que hemos dedicado observación, investigación y reflexión, es la boda de Guillermo y Catalina, en abril de 2011.

PALABRAS CLAVE: Web 2.0 - Relaciones Públicas - Estrategia de comunicación Protocolo - Redes sociales

\footnotetext{
1 Autor correspondiente:

Emilia Smolak-Lozano: Universidad de Málaga. España.

Correo: emilialozano@alu.uma.es
} 


\title{
WEB 2.0 AS COMMUNICATIONS STRATEGY IN PROTOCOLARY EVENTS AND PUBLIC RELATIONS. BRITISH ROYAL WEDDING (24 APRIL 2011)
}

\begin{abstract}
With the explosion of interactive resources called Web 2.0, communication has evolved in order to adapt to the present era and the transience of information within the new communication horizon that is the Internet. New audiences, that nowadays have different parameters and demands in comparison to traditional audiovisual passive audience, have required the implementation of this adaptive effort in communication. This change affects communication model in multiple ways: distribution of the information as well as the broadcasting of the major international events in the politics and protocol, which have also undergone the process of adaptation to advances in Web 2.0 technology, described by following features: interactivity, participation, proximity, practical immersion of the receiver into real time broadcasting. Three great events have affected the paradigms of broadcasting of the major events in politics and protocol. First event was the wedding of Queen Elizabeth of England in 1947, which was the first real time transmission in various countries around the world. The second was the one that managed to attract the largest global audience in real time: the wedding of Diana of Wales and Prince Charles of Wales (broadcasted on TV). The third event which is the subject of present article is the wedding of William and Catherine, in April 2011.
\end{abstract}

KEY WORDS: Web 2.0 - Public Relations - Communication strategy - Protocol - Social networks

\section{INTRODUCCIÓN}

El 29 de Abril de 2011 se produjo en Londres el enlace entre el príncipe Guillermo de Inglaterra y Catherine Middleton. Al margen del acontecimiento mediático en tanto que notorio por la cobertura periodística recibida (el cuarto enlace británico retransmitido, tras el de la Reina Isabel en 1947, el de Carlos y Diana en 1981 y el de Andrés y Sarah Ferguson en 1986), nuestro interés investigador se ha centrado en el uso por primera vez de las conocidas TICs del mundo 2.0, y su incidencia en reflejo de los principios protocolares y ceremoniales.

En el presente estudio, vamos a analizar cómo una fuente de poder, la Casa Real Inglesa, ha realizado una comunicación formal en la que ha aparecido una fuerte presencia protocolar (grande es su tradición, reglamentada por la costumbre y el ducado de Norfolk), y por primera vez, desde los tres enlaces anteriores, en los que el protocolo trató de imponer su visión y normativas (sólo hay que consultar las fuentes de la retransmisión de la boda de la reina Isabel II, en 1947), dada la evolución temporal lógica, ha aparecido una boda real inglesa, concretamente la del nieto de la 
Web 2.0 - Relaciones Públicas - Estrategia de comunicación - Protocolo - Redes sociales

soberana inglesa, Guillermo (William) en los medios de comunicación online y en la esfera del 2.0.

¿Cómo ha sido esta retransmisión? ¿Eran los periodistas conscientes de cómo gestionarlo? ¿Se dirigieron a los canales oficiales? ¿Produjeron la expectación adecuada? ¿Y los públicos? ¿Se dirigieron, dentro de la miríada de canales que Internet ofrece a los lugares indicados por los expertos en comunicación? ¿O se dirigieron a otros? ¿Cuál fue el papel y la atención prestada a las Redes Sociales, que hoy por hoy canalizan gran parte de la información informal? ¿Y cómo fue la aparición y percepción del protocolo y la ordenación, el ceremonial y la etiqueta a través de estos canales online?

En este estudio, trataremos de responder algunas de estas preguntas.

\subsection{Definiciones}

Igualmente se deben clarificar y concretar los modelos y definiciones que entran a formar parte integrante de este estudio, como elementos referenciales y marco teórico.

En este punto, teniendo en nuestras manos, pues, el análisis de un a) evento de relaciones públicas online; b) protocolo y ceremonial $\mathrm{y}, \mathrm{c}$ ) un evento inmerso en el 2.0, debemos, como ya se ha dicho, clarificar algunas definiciones.

En el caso de las Relaciones Públicas, la definición de la International Public Association (IPRA) es: actividad de dirección de carácter permanente y organizado por lo cual una empresa o un organismo privado o público busca obtener o mantener la comprensión, la simpatía o el concurso de aquéllos con los que tiene o puede tener que ver (Castillo Esparcía, 2009:15) Las relaciones públicas online tienen que seguir algunas normas y reglas de uso y realización para ser efectivas. Holtz (2002) ha recomendado en su libro cómo se deben llevar las relaciones públicas en Internet, qué hay que tener en cuenta y ha listado los consejos sobre esta actividad. Por otro lado, el protocolo y el ceremonial, tan ampliamente comentados en los medios, también tienen su importancia y necesidad de ser reflejados. Como definiciones, nos acogemos a la dada por Otero Alvarado (2001):

Planteamos por tanto que el protocolo constituye un primordial elemento de comunicación no verbal, que aplica técnicas formalmente normativas [...] en determinadas ceremonias y cuya función es ordenar el ámbito espacio-temporal en que se desenvuelve el poder establecido con el objetivo de establecer unas óptimas relaciones entre sujeto-emisor y sujeto-receptor en un proceso de relaciones públicas institucionales o corporativas.

Por supuesto también debemos clarificar la definición adoptada en este escrito sobre el término celebridad. Una celebridad es alguien que no sólo tiene fama, sino por el que el público siente curiosidad e inquiere, deseando averiguar más datos de él o ella. La justificación del interés por el término, se debe a que los dos protagonistas del enlace, 
William y Catherine, se han convertido de famosos en celebridades. Sobre todo en el caso de la segunda cuya vida ha sido siempre más discreta que la del joven príncipe. Pero este evento los ha movido directamente a la esfera de las celebridades, dado el seguimiento mediático.

\section{METODOLOGÍA}

Se ha utilizado el método de análisis de contenido y estadísticos para, por un lado analizar el contenido de los perfiles y publicaciones digitales y por otro lado evaluarlos en los términos de cantidad de apariciones, notoriedad y visibilidad.

Hemos elegido los portales tanto oficiales de la monarquía como los portales no oficiales creados por los medios de comunicación y los fans relacionados con la boda real. Hemos enfocado nuestro análisis en los portales ejemplares de estas dos categorías que tienen la mayor cantidad de los suscritos y se especializan solo en el tema de la boda real de este año. Hemos comparado sobre todo los perfiles oficiales y no oficiales en Facebook, Twitter y Youtube para encontrar y describir las pautas de estrategias comunicativas de este evento.

Para la evaluación estadística hemos utilizado las técnicas proporcionadas por programas profesionales de análisis de Twitter que evalúan la intensidad y las pautas de Twitter por los perfiles relacionados con la boda real: Twitalyzer, Tweetstats y Tweetreach. Para evaluar la popularidad, la influencia y la visibilidad de los perfiles en las redes sociales mediante las programas Socialmention y Howsociable.

Hemos investigado a través de análisis de contenido de las múltiples plataformas comunicativas online, rastreando la actividad de relaciones públicas en entornos digitales para este evento protocolar en concreto, y las estrategias implicadas: Youtube, Twitter, Facebook y las actualizaciones online en periódicos (españoles e ingleses) que aplican los recursos del 2.0, como Telegraph y El Mundo. Hemos comparado la utilización de estrategias digitales por parte de las fuentes primarias como Clarence House y las fuentes secundarias de los periódicos e internautas. El tiempo de análisis era un factor a tener en cuenta dada la fugacidad de los eventos en el entorno online: el día de la boda y los dos posteriores centraron nuestra atención.

Para examinar el contenido hemos creado las tablas de contenido y de las características de los perfiles y del contenido de los periódicos digitales con las variables adecuadas al estudio.

Además, para completar el análisis hemos utilizado los artículos de Telegraph relacionados con el tema de la boda real pero de la perspectiva de social media, medios de comunicación en general, política y sociología de la cultura. Estas publicaciones han aportado muchas informaciones útiles para interpretación de los resultados teniendo en cuenta específicamente el entorno socio-cultural de Reino Unido y su protocolo y ceremonial real, que tiene un papel especial en la sociedad contemporánea británica. 
Web 2.0 - Relaciones Públicas - Estrategia de comunicación - Protocolo - Redes sociales

El objetivo es comprobar qué imagen se ha proyectado a través de las herramientas de comunicación online, analizando la presencia en las redes del evento y el uso de herramientas de social media. Así podremos también evaluar la presencia y el uso de las redes y aplicar el análisis de contenido.

\section{ANÁLISIS Y DISCUSIÓN}

\subsection{Las Relaciones Públicas Online}

El cambio de la práctica de la comunicación y el desarrollo del entorno online ha traído las nuevas formas de RR.PP. llamado Relaciones Públicas 2.0, que es, básicamente aplicarlas a los medios sociales de comunicación-social media. El funcionamiento de este nuevo tipo de gestión de reputación e imagen se basa en tres normas: la actividad, la conexión y la proximidad. El funcionamiento de las redes sociales se debe al concepto de 3C de Prof. Orihuela (Fernández, 2011: 138) que implica: comunicación, comunidad y cooperación. Las normas y conceptos anteriormente mencionados afirman que la presencia y el uso de redes sociales online debe ser realizada por las instituciones con el fin de satisfacer las necesidades de los nuevos ciudadanos que demandan la información interactiva, participación igualitaria en la creación del evento y responder a los desafíos de la nueva forma de comunicación online. El objetivo de estas estrategias en organizaciones públicas es satisfacer las necesidades de participación y de formar parte del gran evento ceremonial por parte del pueblo tal como el objetivo principal de los populares periódicos digitales es contribuir la información de interés de los grupos de fans de una celebridad particular con los fines de lucro.

Los últimos análisis de marketingdirecto.com han demostrado que las tendencias del 2010 en marketing y comunicación reflejan las pautas descritos anteriormente afirman que el control de los resultados de estrategias comunicativas es necesario.

\subsection{Web Social y los conceptos de las redes social online}

Los medios de comunicación y los medios digitales han evolucionado en su mayoría debido al proceso de socialización digital, que es impulsada por la innovación del usuario y la popularización del software social. La aparición de prosumer ha creado "nueva generación" de nación digital que forma la parte constitucional de la Web Social (Fumero y Roca, 2007: 45). Según Boyd (2003), el funcionamiento del software social se basa en normas tales como: apoyo a las interacciones de conversación en tiempo real (mensajería instantánea y colaboración), el apoyo a las cotizaciones sociales que crea una reputación digital y el apoyo a las redes sociales (las expresiones y gestión y creación de las relaciones). La Web Social se define como un servicio tecnológico y social de la productividad personal (Fumero y Roca, 2007: 46). Esta perspectiva nos hace centrarse en el estudio sólo en las redes sociales online. Las redes sociales son las plataformas que permiten crear la red personal y estar conectado con esta red, así como para comunicarse con el grupo de personas en tiempo real que es 
factor muy importante en el caso de los fans para quienes Internet y sus redes son las herramientas principales de la actividad. Las redes sociales sirven para construir y gestionar la identidad y la reputación de la persona u organización inscrita en la red que ha llegado hasta la Casa Real inglesa. Los sitios de red online distribuyen cualquier información en cualquier formato, comparten esta información en la forma inmediata y unen a muchos tipos de actividades: charlas, mensajes, comentarios, compartir contenidos, la búsqueda de trabajo y mantener relaciones formales e informales en la misma plataforma. Las plataformas sociales online son la fuente de generación de contenidos personales y de su consumo. Gracias a las redes sociales las relaciones desarrolladas entre los usuarios son confiables y contribuyen al desarrollo profesional o personal, debido a la posibilidad de crear los grupos de especial interés y afición como los grupos de fans. Este tipo de plataformas digitales permiten, así como para aumentar las posibilidades de contactar con otros usuarios. Por un lado, permiten formalizar las redes informales, por otro lado para visualizarlos. Por otra parte, la identidad que se implementa en redes sociales online es real lo cual afecta a la reputación de la persona $u$ organización siendo capaz de aumentar la influencia o dañar la imagen. Fernández (2011) resume las funciones de las redes sociales digitales de la siguiente manera: el acceso a los contactos, la confianza, la visualización de las redes informales, la capacidad de disminuir el rango de grados que separa a un usuario de otro debido a la transparencia, la capacidad de compartir el información y cooperar, facilitar el intercambio de ideas y conversaciones $y$, finalmente, aumentar el nivel de impacto y compartir la información relevante para crear el imagen debido al uso de de identidad real (offline). El último punto es especialmente importante para la presencia de la organización en las redes sociales online. Existen varios tipos de las plataformas sociales online que, además, todavía están en proceso de diferenciación. Teniendo en cuenta los objetivos del estudio, los más importantes son las de la siguiente manera: microblogs con herramientas sociales (Twitter), los sitios de contenido compartido (Flickr y Youtube), redes sociales horizontales (Facebook, Tuenti o MySpace) y las redes sociales verticales (Linkedin, Xing).

Este párrafo está dedicado a la breve caracterización de las características formales y del uso de las redes más importantes en base del análisis de las redes de Fernández (2011). Para empezar, Twitter es una plataforma abierta que permite la comunicación rápida e instantánea en tiempo real, difusión de la información y la creación de una gran capacidad de viralidad. Es la herramienta fácil de integrar con otras plataformas de las cuales puede ser la mayor ventaja en caso de usuarios más activos y poderosos. Facebook es una herramienta de red principal que sirve para la comunicación entre los usuarios, la comunicación de la imagen o la identidad, la comercialización de la organización o del producto y la herramienta de la gestión de la red.

Y los últimos ejemplos son Flickr y Youtube, que sirven para conectar a sus usuarios a través de los medios de compartir fotos y videos para encontrar otros usuarios con intereses similares en áreas particulares.

Aunque los objetivos pueden ser diferentes y por lo tanto las funciones de las redes en particular, los principios son comunes para cualquier plataforma y puede ser 
Web 2.0 - Relaciones Públicas - Estrategia de comunicación - Protocolo - Redes sociales

descrito como otro concepto de 3C: Conectar, Contactar y Comunicarse.

\subsection{Comunicación y Relaciones Publicas online.}

Hoy en día, la comunicación online es el flujo constante de contenidos digitales. El proceso de comunicación en la web social se caracteriza por una respuesta inmediata, el contacto directo y personal en tiempo real, intercambio de contenidos y el intercambio de ideas, la cooperación y la posibilidad de contactar con el grupo ilimitado de personas como es especialmente popular en el caso de los fans con independencia de la zona de situación geográfica y del tiempo. Por otra parte, la comunicación online se procesa a través de diversos medios digitales y sus diferentes tipos (web, buscadores, correo electrónico, blogs, redes, SharePoints, teléfonos de Internet, foros, chats, etc.) lo que implica la interactividad, la interconectividad y la participación activa.

En cuanto a RR.PP online se refiere (Smolak - Lozano, 2011), se puede definir las Relaciones Públicas directas como en el formato digital, que es interactivo, inmediato y se lleva a cabo dentro de la comunidad virtual (aplicando la teoría de Victoria Mas a la RR.PP online, (2001: 136). Las Relaciones Públicas online realizadas en la Web Social se llama RR.PP 2.0 o Social Media Public Relations.

\subsection{El Protocolo y el ceremonial}

En la gestión y creación de eventos donde celebridades, autoridades y personas relevantes intervienen, el uso del protocolo, como consta en la definición de este estudio, permite una ordenación espacio-temporal del poder establecido. Una relación de los poderes que, en su aparición permite la identificación por parte de público de la estructura concreta en ese acto del poder en sus personificaciones físicas. La ordenación crea esa sensación y facilita la asimilación de esos datos de manera consciente o no. Las posiciones relevantes en el encuadre y la cercanía al poder que oficie, son elementos relevantes que entran en la ordenación y la percepción.

En un evento como el que nos ocupa, a saber, la boda real inglesa, el protocolo está más que patente (dirigido por el duque de Norfolk). Pero ese protocolo, todo ese sistema creado (y amplificado en este caso) para la percepción ajena del sistema y estructura del poder, se va a encontrar con el nuevo horizonte comunicativo, que es el 2.0 .

Una ceremonia de gran fasto, aunque por motivos circunstanciales más austera de lo que fueran las anteriores bodas, que congregará a los principales dirigentes de las familias reales europeas y de estado, pese a no ser de un heredero directo, sino del hijo de éste.

Así, el protocolo en eventos, ya sean de tipo oficial o no oficial, privado o público, permite ordenar, como ya se ha dicho en palabras de Otero, el poder espaciotemporalmente. 
Sin embargo una de las intencionalidades que se observaron en la ceremonia fue la intencionalidad de crear un evento que acercara a la monarquía de nuevo al pueblo, pues alguno de sus símbolos más representativos (como Lady Diana Spencer) ya no estaban y se creó la separación entre el pueblo y la de por sí fría casa real, con sus protocolos y ceremoniales. La aparición en escena de Catherine Middleton ha dado la excusa perfecta a la Casa para sacar su armamento pesado y apostar fuerte por una ceremonia y una cobertura sin precedentes, como se verá, en la que el protocolo tiene un papel principal a la vez que discreto, pero que permitirá establecer los límites y dimensiones estructurales en la percepción del poder.

\section{CONCLUSIONES}

\subsection{Las Redes}

En cuanto Facebook, se puede observar las diferencias significativas. El perfil oficial tiene menos fans que uno que es casi la copie del oficial, pretendiendo ser un perfil creado por el grupo de fans mientras en realidad es un portal creado por la empresa especializada en la tema de pareja con su tienda online. Aprovechándose de la ocasión la empresa ha creado una comunidad de carácter cotillero relacionado con boda para promocionarse y conseguir de este modo unos objetivos comerciales. El portal oficial se dedica a publicar los temas importantes y significativos acerca de la boda y la vida de pareja real pero en su dimensión pública. Además se deshabilitado la posibilidad de las publicaciones en el muro mientras que los comentarios pasan por la censura de los community manager. Por los temas de publicaciones que suelen tener alguna importancia para la sociedad y posición de la familia real podemos concluir que el perfil se ha desarrollado con el fin de construir y gestionar imagen de la pareja real, del evento y a través de esto de la imagen de la casa real. El otro perfil tiene como objetivo publicar todas las noticias y servir como medio de informaciones actualizadas y relevantes acerca del evento y de la pareja real. Está un poco más completa, más audiovisual e interactiva pero no trata el tema con la seriedad de la familia real enfocándose en el beso de los novios, vestidos, cotilleros de clase alta y los demás temas, a lo mejor por eso tiene más popularidad. Se puede señalar que la página no oficial es un intento de confundir los usuarios usando los mismos elementos de la identidad como foto y el nombre. Aquí se demuestra el fallo de la estrategia comunicativa de la casa real que no hace nada contra la replicación de su perfil oficial que en todo caso hace daño a un imagen público que la familia real quiere tanto controlar. Hay que señalar que la actitud del pueblo era positiva que se expresaba en los comentarios llenos de emociones positivas, movidas y felicitaciones o mejores deseos.

Twitter era la red más utilizada en la época de la boda real. Tiene mucho más perfiles de tipos oficiales, fans y de los medios de comunicación. Uno de ellos que se dedicó a transmitir la boda minuto por minuto de forma completa, respetuosa, con buenas maneras y cuidado por la imagen real era el perfil de Clarence House. Su objetivo era mantener distancia necesaria para la posición de la institución real pero acercándose al 
pueblo y satisfaciendo sus necesidades informativas. Ha sido todo muy controlado y gestionado profesionalmente. Las fotos eran permitidas solo de los perfiles oficiales y cooperadores o relacionados con este. Similarmente las felicitaciones y comentarios-la mayoría procedió del propio perfil y otros perfiles oficiales. Este perfil tenía un valor educativo ya que informaba sobre cada elemento de la ceremonia, lo explicaba y daba un significado para hacer los usuarios entender la importancia y simbólica del evento, lo cual ayudaba enormemente en cuanto a parte de la interpretación del protocolo, casi como labor traductora. Este perfil es también el más popular, 152.000 de seguidores con una cantidad significante pero no excesiva de las publicaciones sobre 900 . El perfil era muy activo, bastante interactivo, con muchas publicaciones y actualizaciones de cada detalle de la boda y de la vida pública de los príncipes.

El otro perfil específicamente creado para la boda se llama Royal Wedding 2011 y tiene casi 500 de Tweets hechos principalmente y en su mayoría en el día de la boda. Tiene menos seguidores - alrededor de 97000. Su última actividad ha sido en mayo y similarmente al perfil oficial en Facebook no ha sido actualizada.

Lo que es significativo aquí es el hecho que el tercer perfil analizado es un perfil de los fans creado para este evento que sigue mantenido y actualizado. Tiene mucho menos fans que otros como 500 y se dedica a cotillero, sensación y lo que esta controversia o llamativo sobre el evento y la boda real. Este perfil aunque no tiene gran audiencia es el más activo con 8000 publicaciones. Podemos concluir al principio ya que tema demanda una profundización que los usuarios de Twitter al contrario de Facebook no buscan el cotillero ni sensación pero quieren ser bien y culturalmente educados e informados mientras los de Facebook buscan más el entrenamiento.

Las mismas conclusiones se pueden aplicar a Youtube que ha servido como el canal principal y más popular de transmisión online en vivo de la boda real. La transmisión se produjo mediante el canal oficial - Royal Channel - de forma de livestream. Este canal tiene más de 118000 seguidores y contribuye con los 337 videos. Lo que llama atención es el hecho ya señalado por los expertos que el canal sirve para construcción de imagen controlado ya que se ha excluido la posibilidad de los comentarios manteniendo solo la opción de ratings. Resumiendo este análisis podemos destacar 3 tendencias principales en el uso y aplicación de los perfiles de las redes sociales: que los perfiles oficiales se dedican a realizar un objetivo de gestionar imagen por el precio de violar los mecanismos de las propias redes como interactividad por lo cual apuestan por el control de las publicaciones con la orientación educativa e informativa como era diseñado en las estrategias de comunicación de la casa real.

El otro es, el uso instrumental de las redes particulares, Facebook para diversión y Twitter para informarse lo que se refleja en la cantidad de los seguidores de los perfiles oficiales y no oficiales en cada de las redes.

La última es el nuevo uso de Youtube como el canal de forma televisiva de la transmisión de los eventos de alta importancia protocolar en el nivel mundial a la audiencia masiva. 
Los temas que dominaban las publicaciones eran sobre el vestido de novia, el beso en el balcón del palacio, conversaciones de los novios durante la ceremonia, moda, la familia de la novia, comida, fiestas y celebraciones en el mundo.

\subsection{Los Periódicos}

\section{$\underline{\text { La boda real en el mundo según Telegraph. }}$}

Antes de empezar el análisis detallado de los periódicos seleccionados hemos comprobado cómo se ha cubierto el evento de la boda real en los medios de comunicación en los países seleccionados. Primero, más de 20 millones de la gente se esperaba estar viendo la boda real en televisión indicando y hacer predicciones de un record televisivo de la era moderna de múltiples canales. En Francia se estima dos millones de televidentes de la boda real. Mientras los italianos fueron hechizados por la boda real. El evento fue salpicado a través de sitios web de noticias, transmitido en directo por una media docena de cadenas de televisión y dominó las portadas del sábado. Muchos japoneses trataron la boda real como una oportunidad para alejarse mentalmente de la tragedia del 11 de marzo del terremoto, tsumami y desastre nuclear que devastó el norte de su país. Emisora nacional NHK hizo gran parte de la pompa de la ocasión. Los japoneses mantienen su propia familia imperial en alta estima y tienen sentimientos similares hacia la familia real británica, por lo que ha habido un gran interés por la boda real. Australia estaba bien y verdaderamente arrastrado por la fiebre de la boda real mediante la transmisión en vivo, periódicos y diarios llenos de imágenes a color de la pareja feliz y excelentes críticas de la gran ocasión. Periódicos en Oriente Medio el Golfo contó con la boda real en gran medida - pero sin fotografías del beso en el balcón, la imagen que se muestra en cientos de portadas de todo el mundo. Sin embargo en otros países de esta zona geográfica los comentario de los medios de comunicación era críticos y en su mayoría muy negativos. El Diario del Pueblo, el periódico oficial del Partido Comunista de China, decidió que la boda real no mereció ni una sola palabra de la cobertura. El beso en el balcón dominado las primeras páginas en un Estados Unidos que quedó fascinada con la boda real. Millones de estadounidenses vieron en directo por Internet ya que la boda tuvo lugar, temprano en la mañana en la mayoría de los lugares en los EE.UU.

El diario inglés Telegraph era el que más publicaciones tenía ya que se ha dedicado especialmente al tema de la boda en los días del evento por su interés procedente de los orígenes del periódico. Se ha observado casi 500 publicaciones de los diferentes tipos desde artículos, por fotos hasta los videos y editoriales especializados en la moda, medios de comunicación, etc. En comparación con 8 artículos en El Mundo y sólo 2 en El País en sus versiones digitales, Telegraph ha hecho un uso extensivo del tema. De hecho ha creado y dedicado muchos servicios especiales para la boda real: Galería de fotos, Telegraph TV, recap de la boda, Videos, Twitter live, live stream, Royal Wedding Latest and Live, Live Coverage, Fashion de la boda Real, Broadcast, Boda en las fotos, RW minuto por minuto, Wedding Book, Wedding Highlights, map, fotos en Slideshare. 
Web 2.0 - Relaciones Públicas - Estrategia de comunicación - Protocolo - Redes sociales

En cuanto de las redes aplicadas por los periódicos se han hecho botones de las principales plataformas 2.0, hasta un total de 12 en el caso de Telegraph. Mientras los periódicos españoles no tiene uso desarrollado de las herramientas de social media basándose en las aplicaciones simples como comentarios, ratings, tweets y retweets, Telegraph ha utilizado una gama amplia de las herramientas de social web: RSS, Likes, comentarios, RSS, report, recomendar, blogs, mensajes de Twitter, quizzes, preguntas, concursos, ratings, favoritos, respuestas, retweets.

Como podemos observar a pesar de amplia cobertura en los medios internacionales, el ejemplo del diario inglés nos sirve para señalar que por la gran importancia del evento protocolar de la boda real los medios ingleses han aprovechado al máximo las posibilidades de la web social y se han dedicado al tema con una actitud muy intensiva y activa enfocándose en cada detalle y aportando las interpretaciones de cada perspectiva de la vida social.

\subsection{La Evaluación Estadística}

Según el análisis de Socialmention, la boda real indica 4 veces más actitud positiva que negativa pero con una dominación de la actitud neutral. Las palabras calves más importantes son: wedding, royal, kate, middletone, William. Entre los usuarios principales relacionados con el tema se encuentran el perfil oficial de Royal Wedding UK y el perfil cotillero katewilliam2011 entre otros. Los principales hashtags son royalwedding, wedding, William. Las fuentes principales de las noticias es Twitter, idéntica, photobucket y paginas de compartir fotos como Picasaweb y Flickr. Podemos ver que el evento ha ganado alto nivel de notoriedad y que el papel principal fue jugado por microblog Twitter.

La visibilidad del evento en el ámbito de los medios sociales tras meses después de la boda sigue siendo bastante alta, estimada por Howsociable a 634 en su escala propia. Esto significa que el tema sigue siendo importante e interesante para la sociedad. Entre redes analizadas en este estudio la mayor visibilidad tiene la boda real en Twitter y Youtube ya que ellos eran los canales principales de la trasmisión y fuentes de información quitado este rol de Facebook. Después la visibilidad en Flickr fue de 467 - ya que es la página más popular de compartir las fotos de este evento y con el resultado la mitad de lo de Youtube - en Facebook con 342.

En el caso de Wildfire Wedding Royal perfil de Facebook ha anotado el crecimiento en los fans de $2 \%$ y ha recibido el rango bastante alto en entorno de social media de 100 puntos que refleja la importancia del evento en este ámbito online.

Según los datos de Twitstats, sólo en Agosto se ha enviado más de 300 tweets relacionados con el tema de boda de los príncipes, 13 al día. Para el día de boda hubo una media de 152 tweets en total por minuto, la mayoría ha sido enviada en viernes de la celebración con un pico en la cantidad de publicaciones per minuto a las 2 después de la celebración. La mayoría provenientes de Clarence House y de los periodistas y eran gestionados a través de Tweetdeck. Las respuestas similarmente fueran dirigidas 
a Clarence House y periodistas.

Según Twitalyzer, royal wedding tiene perfil en Twitter como un joven británico de 25 hasta 34 años, con un rango de 99 similar a lo de Wildfire. Su impacto hoy en día es casi $20 \%$ pero sin ningún influencia e involucración en el entorno digital. Está poco retweeteada y no le interesa la interectividad ya que sigue pocas personas siendo el interés de las muchas.

Para resumir, el alcance de los tweets es alto. Según Tweetreach las 50 últimos tweets llegan a más de 15.000 personas, de que la mayoría en $90 \%$ son tweets regulares que provienen de katewilliam2011 y royalwedding. Junto se ha producido más de 67000 de impresiones de los cuales la mayoría son tweets enviado con frecuencia 4-7 y singulares.

En general, podemos concluir con las palabras de Richard Fitzwilliams, experto en la casa real británica (El Mundo, 30 de Abril de 2011): “La boda está marcada por la tecnología, aunque no de forma excesiva ya que según El Mundo, la Familia Real ha prohibido twittear la ceremonia o subir fotos a las redes sociales".

Sin embargo, los expertos opinan de esta estrategia de manera negativa: anunciarlo en Twitter y Facebook fue una manera inteligente de crear la noticia, pero que prohíban que se 'tuitee' es demasiado. No deben hacer recomendaciones que coarten la libertad de expresión porque además, no van a poder evitarlo. Tienen que entender que los privilegios en el control de la información se han terminado incluso para la monarquía británica [...]. (Gutiérrez-Rubí, El Mundo, 30 de Abril de 2011).

Hay que señalar, tras la nuestra análisis, que realmente en el perfil de Facebook, Twitter y Youtube aportaciones de cualquier tipo de otros usuarios eran deshabilitados, removidos o pasaron por la censura de los responsables de comunicación en las redes sociales si procedieron de los perfiles institucionales o cooperadores. Esto era anunciado directamente en el perfil o se podía observar en los tipos de publicaciones y sus contenidos.

La exclusión de las aportaciones individuales de los usuarios sirve para controlar el flujo de información en los portales sociales ya que "con esta boda se está haciendo un gran trabajo de construcción de marca, de imagen de personaje público". (GutiérrezRubí, El Mundo, 30 de Abril de 2011) que es una estrategia unidireccional que no cabe bien en el modelo nuevo de comunicación online que es típico para la comunicación en las redes sociales, respondiendo a una estrategia bien planificada.

Con esta táctica no solo se ha transmitido cada minuto o paso de la celebración pero se ha puesto acento adecuado a su significado y rol en el mundo contemporáneo y ha transmitido hacia al pueblo el papel de monarquía en la cultura, historia y entrono social de Reino Unido.

Se ha conseguido el objetivo de obtener un imagen positivo de la familia real y acercar 
Web 2.0 - Relaciones Públicas - Estrategia de comunicación - Protocolo - Redes sociales

a la gente ya que en los comentarios en los portales no oficiales.

Sin embargo, tanto en la comunicación como en la organización de la boda se han gobernado por los principios de mantener la ceremonia modesta, mantener el balance entre la consideración por la austeridad de los tiempos presentes y la necesidad por el espectáculo satisfaciendo las expectativas de los espectadores y demandas propias de este tipo de ocasión. El objetivo de emisión controlada de imagen del evento y través de esto de la imagen de Casa Real era un beneficio patriótico de profundizar las relaciones entre el pueblo y el estado representado todavía por la monarquía británica.

En nuestra opinión se ha conseguido demostrar el evento con una señal del poder y significativa posición que ocupa la familia real mezclando con transmitir la majestuosidad de la institución y mantener al mismo tiempo un sentido de informalidad necesaria para conseguir la actitud amable del pueblo en el nivel internacional. Como lo decía un titular en el diario The Washington Post en una fotografía del beso en el balcón: "Ese beso segundo sellado". Prince William y Kate ha concesionado el deseo de la gente con una celebración de la juventud, la realeza y todo lo británico".

La boda real fue presentada entre otros en los siguientes servicios online como: officialroyalwedding2011.org, twitter.com/ClarenceHouse (relación minute-porminuto), www.thesundaytimes.co.uk con un servicio especial de la boda real.

Nosotros encontramos la presencia de la boda real, usando la palabra clave "royal wedding" en los buscadores de Google en las siguientes redes sociales:

\subsection{La transmisión}

Para resumir, se calcula que casi 2 mil millones en más de 180 países de todo el mundo se esperaba para ver las noticias y reportajes, fotos e imágenes de televisión de la boda real, que fue cubierto por más de 8.500 periodistas en Londres solamente. Facebook calcula que las personas el número de 2.8 million en Gran Bretaña y En Estados Unidos se escribían las actualizaciones en el "muro" acerca de de la boda real en las 24 horas antes del comienzo del servicio. En la preparación para la ceremonia, los usuarios de Twitter publicaron 237 tweets cada segundo sobre la boda real.

Para terminar, nos permitimos a usar el comentario de The Australian, periódico nacional del país, que afirmó que la boda real ha realizado el objetivo de renovar la monarquía. La boda de Principe William y Catherine Middleton ha marcado un hito en su esfuerzo largo de reparación del interés de Familia real y un mojón hacía un futuro no seguro y diferente de unos de los clanes reales más prominentes del mundo. El hecho de que el evento ha sido transmitido en YouTube y Twitter por Clarence House ha señalado que Familia Windsor ha cogido las pautas de los asesores de imagen de las corporaciones y celebridades con el objetivo de formar este futuro con mucha precaución. 


\section{REFERENCIAS}

Castells, M. (2009): Comunicación y Poder. Alianza Editorial, Madrid

Castillo, A. (2009). Relaciones Públicas. Teoría e historia. Editorial UOC Barcelona

Fernández, S. (2011): Dos grados: Networking 3.0, LID Editorial Empresarial, Madrid

Fumero, A. y Roca, G. (2007): Web 2.0, Fundación Orange, España

Goban-Klas, T. (1999). Media i Komunikowanie masowe. Teorie i analizy prasy, radia, TV i internetu, Kraków: Wydawnictwo Naukowe PWN.

Holtz, S. (2002). Public relations on the Net: winning strategies to inform and influence the media, the investment community, the government, the public, and more!(2nd ed.). New York: Amacom

Lenderman, M. Sánchez, R. (2008): Marketing experiencial.La revolución de las marcas, Madrid: ESIC Editorial.

Maciá Domene F., Gosende Grela J. (2010): Marketing online. Estrategias para ganar clientes en Internet, Madrid: Ediciones Anaya Multimedia.

Maqueira, J. M., Bruque, S.(2009): Marketing 2.0. El nuevo Marketing en la Web de las Redes Sociales, RA-MA Editorial, Madrid

Smolak-Lozano, E. (2011): Relaciones públicas en las redes sociales. Publicity personal de los usuarios privados de facebook. El modelo, las estrategias y la evaluación, Revista Icono14,Número A6, 2011, Madrid, pp.341-367

Van Dijk, J. (1991): The Network Society: Social Aspects of New Media, Bohn Staflen Van Loghum, Houten.

Victoria Mas J. S. (2001): Nueva publicidad, Comercio electrónico y demás propuestas interactivas. Lectura de un mito platónico a vueltas con la "palabra inerte", Universidad de Málaga, Málaga.

\section{Emilia Smolak-Lozano}

Licenciada en Sociología en la Universidad Jaguellónica (Polonia) y Estudios Europeos en la Universidad de Exeter (Reino Unido). En 2011 he realizado el Máster en Gestión Estratégica e Innovación en Comunicación en la Universidad de Málaga, en la cual actualmente estoy terminando mi Doctorado en Comunicación Online, enfocandóse principalmente en el tema de la medición y evaluación de los Social Media.Trabajaba en varios paises europeos en el campo de la medición de audiencia televisiva para Nielsen y últimamente estoy utilizando mi conocimiento académico en cooperación 
con Sotrender.com, una herramienta de medición de marketing en Facebook. Autora de varias publicaciones sobre la comunicación online y ponente en conferencias internacionales relacionadas con la comunicación.

\section{Damián García Ponce}

Licenciado en Publicidad y Relaciones Públicas, Máster en Gestión Estratégica e Innovación en Comunicación y doctorando (PhD Candidate) en Comunicación Organizacional en la Universidad de Málaga. Investiga sobre Hostilidad Comunicativa en entornos online y su efecto reputacional sobre las organizaciones, así como otra línea de investigación en narrativas audiovisuales en videojuegos, investigando los nuevos recursos que se utilizan para convertir estas plataformas en nuevos formatos de narración. 